\title{
Qualis as a Measuring Stick for Research Output in Economics*
}

Bernardo Guimarães ${ }^{* *}$

\begin{abstract}
Qualis is the set of procedures officially used for evaluating research output in Brazil. This paper asks whether Qualis provides a good measuring stick for economic research published in international journals. The answer is not positive.
\end{abstract}

Keywords: Research Impact, Ranking, Economics Journals, Qualis.

JEL Codes: A10, I23.

${ }^{*}$ Submitted in March 2011. Revised in August 2012. I thank Felipe Yamada for able research assistance and Daniel Cajueiro, Braz Camargo, Sergio Firpo, Mariana Newport, Vladimir Ponczek, André Portela de Souza e Vladimir Teles for comments and suggestions.

${ }^{* *}$ São Paulo School of Economics-FGV, Brazil. E-mail: bernardo.guimaraes@fgv.br 


\section{Introduction}

Qualis is the set of criteria officially used for evaluating research output in Brazil. By providing a measuring stick for research output, it influences funding for research activities and the evaluation of Brazilian departments of Economics, thus affecting incentives for researchers. One important objective of Qualis is to assess the impact of our research on the international academic community. The question in this paper is whether Qualis provides a good measuring stick for economic research published in international journals.

Qualis is not only concerned about measuring the impact of research on the international academic community. Another of its objectives is to stimulate research that might help better understand the Brazilian economy. For example, research using Brazilian data can uncover interesting features of the Brazilian economy with important policy implications, even when no methodological innovation is introduced and hence the research has a a negligible impact on the international academic community. Recognizing this potentially important issue, this paper evaluates Qualis as a measuring stick for research published in international journals only. Moreover, research by economists might influence academics in other fields. While that might also be important, this paper is focused on the impact of research on the scientific study of Economics.

Measuring research impact is not a trivial task. Ideally, one would like to know which papers researchers all around the world have read, and how much they have learned from each paper; how much their views were influenced by each paper; and how much each paper is changing the way we think in Economics. Since this is impossible to measure, there are different ways to try to proxy for it. The method employed by Qualis attributes a value to each paper according to the journal in which it was published. This is a widely used method, and will be followed in this paper. ${ }^{1}$

Although there are many methods for ranking journals, there is some evidence that the differences in methodologies do not lead to substantial differences in the evaluation of Economics departments (Krapf, 2011). However, the Qualis ranking is quite distinct from those following other methodologies. Does Qualis lead to different results?

This paper ranks researchers based in Brazil and in the US according to 2 methods: Qualis and an international alternative provided by Combes and Linnemer (2010), CL henceforth.

The take-home points are:

1. The most productive researchers according to the CL weighting list belong to a wide variety of fields in Economics. Many of them could be considered "heterodox", since their research agenda aims at replacing the mainstream view of the profession. This shows that papers that challenge the orthodoxy

\footnotetext{
${ }^{1}$ Citations are also used as a proxy for research impact (see, e.g., Issler and Ferreira (2004)).
} 
are also published in top journals, along with papers that comply with the mainstream.

2. Not surprisingly, in the CL ranking there is a very large gap between the top US departments and researchers and their Brazilian counterparts. However, according to the Qualis-based ranking, that difference is much smaller, for example: the Economics departments in Rio combined would be at the level of some top 10 US departments; some of the top researchers in the sample are based in Brazil; etc. This is in sharp contrast with the general perception of a huge gap between the top US and Brazilian departments in terms of: demand from all over the world for PhD education, post-docs, jobs, etc; prestige within the international academic community; number of plenary speakers in the main conferences around the world etc. The Qualis ranking does not provide a good metric to evaluate the international impact of research of Brazilian departments vis-a-vis international departments.

3. The correlation between points attributed to Brazilian researchers using the Qualis ranking and the points attributed to the same researchers using the CL ranking is low, especially when we control for the number of papers by researcher. The Qualis ranking does not provide a good metric to rank Brazilian economists according to their international publication record.

The results in this paper are related to findings in previous studies (e.g., Faria et al. (2007), Novaes (2008) and Silva (2009)), which will be discussed herein.

Section 2 describes the data and methodology. Results are presented in Section 3 and Section 4 concludes.

\section{Data and Methodology}

The official criteria for evaluation of research output in Brazil, Qualis, classifies journals in 8 categories. A paper from a journal classified as A1 is worth 100 points. Subsequent ratings are A2 (80 points), B1 (60 points), B2 (40 points), B3 (25 points), B4 (15 points), B5 (5 points) and C (0 points).

In order to evaluate Qualis as a measuring stick for research published in international journals, we need to compare it to a well-accepted international journal ranking. The list in Combes and Linnemer (2010) was chosen because:

1. It includes a long list of journals. Most other papers do not include some journals where many Brazilians publish.

2. It is recent, from 2010 .

3. Using the column CLh in CL, the ratio of the value of a paper in the top journals and the points attributed to a paper in a lower ranked journal is actually a bit lower than alternative lists. Figure 1 compares the points 
attibuted by CL and 3 alternative methods (Kalaitzidakis et al., 2003, Kodrzycki et al., 2006, Laband and Piette, 1994). Points attributed to each journal are normalized so that the sum of points attributed to the top 100 journals is the same for all lists. Different from some other methodologies, the top 4 journals in the CL ranking (QJE, AER, JPE and Econometrica) have very similar values. Hence, the distance between the \#1 and the other top journals are smaller in the CL ranking. Moreover, the value of a paper in the \#100 journal is $3.36 \%$ of the \#1 in CL compared to $0.15 \%, 0.71 \%$ and $2.08 \%$ in Laband-Piette, Kalaitzidakis et al and Kodrzycki-Zu, respectively. Dispersion in CL is thus smaller than in other rankings.

The smaller dispersion in the values of journals would (1) favour researchers in Brazil, who tend to publish in less prestigious journals, and (2) make the benchmark closer to the Qualis criterion, since the dispersion in the Qualis ranking of journals is much smaller, as shown in Figure $1 .^{2}$

While the ranking of journals in CL generally agrees with the general ranking of journals in the profession (for example, the top 5 in CL are the well-known top 5 journals), there are biases against new journals that haven't been much cited yet (Theoretical Economics, American Economic Journals) and those that are becoming more important, and in favour of journals that are losing prestige.

Publications in the AER Papers and Proceedings and JEEA Papers and Proceedings were discarded, since the value of contributions in those papers is less clear. Moreover, since this paper is only concerned with Qualis as a metric for evaluating research published in international journals, publications in journals in Portuguese or Spanish were excluded from the sample.

The value attributed to a paper in a given journal is divided by the number of authors for the following reason: if researchers A and B produce 3 joint papers while researchers $\mathrm{C}$ and $\mathrm{D}$ produce 2 papers each (and all papers are identical in terms of quality), $\mathrm{C}$ and $\mathrm{D}$ have to be considered more productive than $\mathrm{A}$ and B. Arguments for giving a higher value to joint papers based on providing incentives for co-authorship are often raised, but I am not aware of any factors that researchers do not internalize in their decisions on co-authoring that have important effects on the profession. In the absence of such externalities, I can't see how distortions in incentives may improve allocation of research effort.

A 5-year period was chosen, so papers published between 2006 and 2010 are considered. Other prestigious rankings also employ 5-year periods (e.g.: Tilburg ranking, https://econtop.uvt.nl/).

\footnotetext{
${ }^{2}$ One could thus conjecture that the difference between Qualis and other international rankings would be even larger. That might be true, but the differences in dispersion among the international rankings might be due not only to differences in methodologies. The smaller dispersion in the most recent rankings (CL and Kodrzycki-Zu) might be reflecting an increase in the number of sub-fields and specialized journals in Economics - which could have led to an increase in the number of journals with an intermediate impact.
} 
Figure 1

Relative values of journals in different rankings

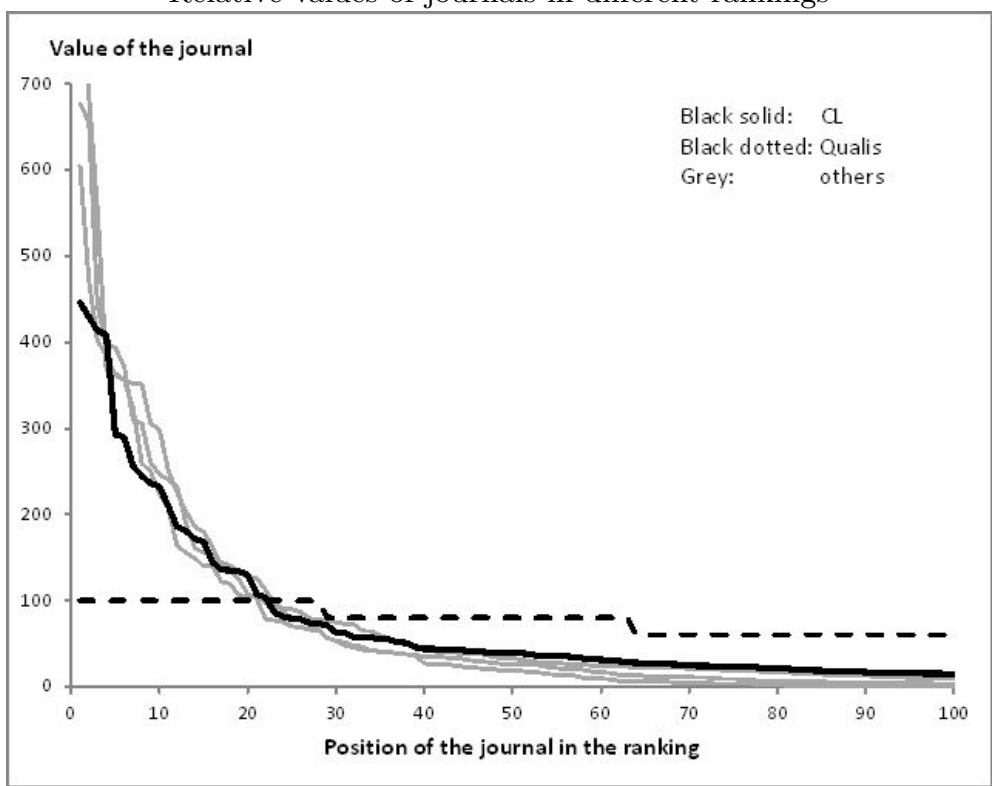

The top 10 US economics departments were chosen according to the US News ranking. The top 9 are MIT, Harvard, Princeton, Chicago, Stanford, Berkeley, Yale, Northwestern and Penn. Columbia e Minnesota are tied in \#10, Columbia was chosen for being ahead of Minnesota in the Tilburg ranking.

The top 10 Brazilian departments were chosen according to the average ranking of incoming Master students in the Anpec exam in 2010. The top 9 were PUC-RJ, USP, EPGE, EESP, UFRJ, UNB, UFMG, Unicamp and USP-RP. The 10th position is not so clear because there was a large disperion in the number of incoming students at UCB, UFPE and UFRS, so a simple average could be misleading. UCB was chosen for being ahead of the other two in a literal interpretation of the criterion.

In total, there were 381 economists in the top 10 US departments and 118 in the top 10 Brazilian departments with positive points in at least one of the two rankings (CL or Qualis).

Information on publications of Brazilian researchers was obtained from the Lattes curriculum system. Fortunately, in most cases, the last update was very recent, not more than a few months before data was collected. Information on publications of researchers in the top 10 US departments were retrieved from their personal webpages. Some of them (especially tenured and older professors) do not seem to update their pages often enough. In those cases, other sources were 
consulted, but the list might still be incomplete.

\section{Results}

\subsection{The CL-based ranking}

Table 1 presents the top 20 researchers of the CL-based ranking.

Table 1

The 20 most productive researchers (CL metric)

\begin{tabular}{llll}
\hline 1 & Peter Phillips & Yale & 804,51 \\
2 & John List & Chicago & 744,13 \\
3 & Daron Acemoglu & MIT & 476,33 \\
4 & Amy Finkelstein & MIT & 466,53 \\
5 & Matthew O. Jackson & Stanford & 441,78 \\
6 & Raj Chetty & Harvard & 427,55 \\
7 & Jesse Rothstein & Berkeley & 379,84 \\
8 & James J. Heckman & Chicago & 377,36 \\
9 & Botond Koszegi & Berkeley & 373,90 \\
10 & Johannes Horner & Yale & 349,43 \\
11 & Esteban Rossi-Hansberg & Princeton & 347,23 \\
12 & Jushan Bai & Columbia & 332,52 \\
13 & Iván Werning & MIT & 324,93 \\
14 & Matthew Rabin & Berkeley & 322,00 \\
15 & George-Marios Angeletos & MIT & 316,98 \\
16 & Benjamin Olken & MIT & 304,52 \\
17 & Dean Karlan & Yale & 301,11 \\
18 & Don Andrews & Yale & 301,07 \\
19 & Yeon-Koo Che & Columbia & 299,29 \\
20 & John Campbell & Harvard & 290,63 \\
\hline
\end{tabular}

There is plenty of diversity in research interest and methods among the 20 most productive researchers. Theoretical econometrics (e.g., Peter Phillips and Don Andrews), applied econometrics (Amy Finkelstein, Ben Olken), macroeconomic theory (Marios Angeletos, Ivan Werning), microeconomic theory (Botond Koszegi, Johannes Horner) and finance (John Campbell) are all represented in Table 1. Some of them have contributions in more than one of those broad categories. In terms of nationalities, Africa seems to be the only continent absent from the table. ${ }^{3}$

Interestingly, many of them could be called "heterodox" because their research

\footnotetext{
${ }^{3}$ Peter Phillips is from New Zealand, Ivan Werning is from Argentina, Yeon-Koo Che is Korean, Botond Koszegi is Hungarian and Don Andrews is Canadian. That covers all continents but Africa.
} 
challenges the mainstream view of the profession and/or proposes alternative views. For example:

- Botond Koszegi (\#9) e Matt Rabin (\#14) do research in behavioral economics. In their models, agents have unorthodox preferences: they are usually irrational; they may be time inconsistent; they might care about relative consumption; they might frame their problems in ways to lead to an inefficient outcomes; etc. The goal of their research is to provide alternatives to the textbook homo-economicus.

- Daron Acemoglu (\#3) is identified with the subfields of Institutional Economics and Political Economy, although he has also important contributions on other subfields, like Economic Growth. His papers often analyze the interaction between an elite trying to maintain its power, and the citizens that are exploited by the elite. Social conflict is a main theme. Some of his research is more related to the work of Prado Jr (1942) than to standard textbook models of economic growth.

- John List (\#2) and Dean Karlan (\#18) belong to the field of experimental economics. Many econometrics textbooks introduce the subject by drawing a distinction between Economics and natural sciences like Chemistry and Biology: while other scientists obtain data from lab experiments, it is much more difficult for economists to perform relevant experiments, hence we have to identify (causal) relations using existing data, which raises important statistical problems. However, researchers like John List and Dean Karlan have actually been running field experiments.

- Marios Angeletos (\#15) is concerned about how beliefs are formed and affect the macroeconomy. One objective of his research is to get a better understanding of Keynes' "animal spirits" - "Sentiments" is the title of one of his recent papers.

The list goes on. Spatial economics is one of the main research interests of Esteban Rossi-Hansberg (\#11). Much of Matthew Jackson's (\#5) research is on networks and social economics.

In Brazil, it is sometimes said that top international journals publish papers that conform with the orthodox view but not those that challenge the mainstream. This top 20 list presents strong evidence against this thesis and supports the view according to which top international journals aim at publishing research that is expected to have a large impact on the way we think about Economics. Papers showing that a mainstream model is appropriate and papers proposing a totally different alternative are all welcome in top journals, as long as they are expected to have a high impact on the scientific study of Economics. 
The researchers in the top 20 list are well known for their high productivity. Some are already world authorities in their fields. Other are younger researchers on the way to becoming some of the world's top academic economists.

There is no representative of the top Brazilian institutions in the top 20 list. Actually, there is no Brazilian in the top 100 of the CL ranking. The most productive research in the CL ranking is Victor Filipe Martins da Rocha (EPGE, \#104), and all the other 149 names in the top 150 are in US departments. In part, this result is specific to the period analysed: if the 2005-2009 period had been chosen, Rodrigo Soares (PUC) would almost certainly be among the top 100 (and probably Carlos Eugenio da Costa (EPGE) as well). Still, as expected, there is an enormous difference between the international impact of research from the top academics in the US and the most productive researchers in Brazil.

Figure 2

Most productive researchers of each institution

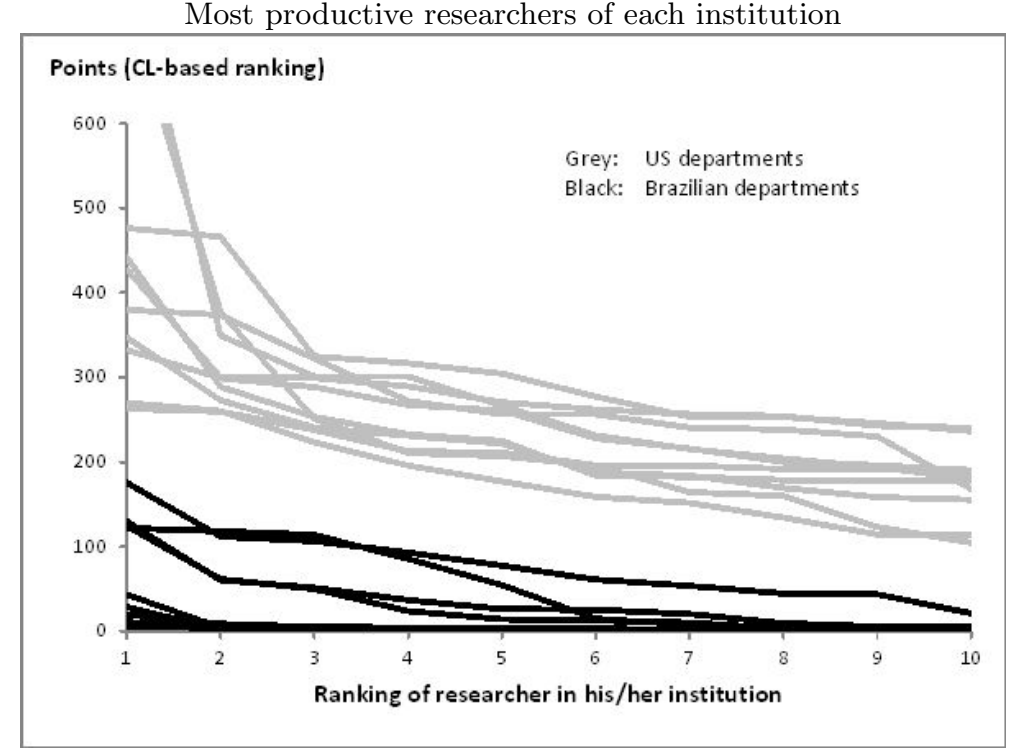

Figure 2 depicts the points attributed to each of the top 10 researchers in each institution according to the CL ranking. Each line represents a department and the horizontal axis shows the rank of a researcher in his/her department according to the CL ranking. While it is difficult to distinguish between all grey or black curves, it is easy to see a very large gap between the top 10 US departments and the top 10 Brazilian departments. ${ }^{4}$

\footnotetext{
${ }^{4}$ One could argue that Figure 2 probably understates the difference between US and Brazilian Economics departments in terms of research impact in the international academic community. The performance in the 2006-2010 period clearly does not reflect the whole career of an academic.
} 
This huge gap is not surprising. Students from all over the world go to the US for graduate programmes; researchers from all over the world want to spend time in the US as post-doctoral fellows; a job at a top US department is generally considered the best possible outcome for all $\mathrm{PhD}$ graduates. It goes without saying that the demand from top international students and researchers for a place in a Brazilian $\mathrm{PhD}$ programme or a post-doctoral appointment is almost inexistent.

The results in Figure 2 are not embarrasing. It is safe to state that the top 10 world departments outside the US would still be far below the top 10 US departments in this ranking, so we should not expect Brazilian departments to be any closer than they are. Actually, Faria et al. (2007) have shown that Economic research in Brazil has been improving significantly.

\subsection{The Qualis-based ranking}

Table 2

The 20 most productive researchers in the Qualis-based ranking

\begin{tabular}{llll}
\hline 1 & Peter Phillips & Yale & 1442,50 \\
2 & John List & Chicago & 1376,67 \\
3 & James J. Heckman & Chicago & 910,83 \\
4 & Daniel O Cajueiro & UNB & 810,83 \\
5 & Benjamin Tabak & UCB/Bacen & 757,67 \\
6 & Daron Acemoglu & MIT & 723,33 \\
7 & Serena Ng & Columbia & 706,67 \\
8 & Angus S. Deaton & Princeton & 690,83 \\
9 & Fuhito Kojima & Stanford & 685,00 \\
10 & Matthew O. Jackson & Stanford & 666,67 \\
11 & Jonathan Gruber & MIT & 661,67 \\
12 & Paulo Klinger Monteiro & EPGE & 653,33 \\
13 & Robert Townsend & MIT & 633,33 \\
14 & John Campbell & Harvard & 606,67 \\
15 & Liran Einav & Stanford & 602,50 \\
16 & Jushan Bai & Columbia & 573,33 \\
17 & Mauro Boianovsky & UNB & 570,00 \\
18 & Marilda Sotomayor & USP & 566,67 \\
19 & Raj Chetty & Harvard & 566,67 \\
20 & Mihai Manea & MIT & 560,00 \\
\hline
\end{tabular}

While the likes of Peter Phillips and Don Andrews have been topping the rankings for 20 years, there are relatively fewer researchers in Brazilian institutions that have been productive for such a long time. Thus, a measure of life-time production (or expected life-time production) would probably yield an even sharper distinction between the black and gray lines in Figure 2 . 
Table 2 presents the top 20 researchers in the Qualis ranking. While there was no Brazilian researcher among the top 100 in the CL ranking, there are 5 researchers from Brazilian institutions among the top 20 according to the Qualis criterion, and 2 among the top 5.

The Brazilian researchers in the top 5 of the Qualis ranking do multi-disciplinary research and publish mostly in Physics journals. This poses a problem to our exercise: this paper attributes to each research the sum of the points obtained in each publication, but for journals outside the field of Economics, that is not the procedure followed by Brazilian government. There is a cap to the number of points an Economics department can get from journals outside the field of Economics, and for decisions on grants for researchers in Economics departments, only publications in journals within the field of Economics are considered. So it is not clear how we should treat these cases. ${ }^{5}$

Despite these non-linearities, it is still curious that some Brazilian researchers are at such high positions in this ranking. Actually, the points attributed to these researchers highlight a big difference between publishing in Economics and in other areas, like Physics. Prestigious journals such as Physical Review Letters and Physical Review E do not accept papers with more than 4 pages - which is in sharp contrast to the editorial policy in Economics. Such differences between disciplines presents some challenges to the evaluation of research output.

Having highlighted this important difference between publishing in Economics and Physics, I decided to exclude publications in Physics journals of the sample owing to the non-linearities mentioned above. ${ }^{6}$

After removing these 2 researchers from the sample, we are still left with 7 researchers based in Brazil above the top 50 in the sample. While there is no question that the Brazilian academics that have made it into this list are very productive researchers, it is also clear that their research hasn't had an impact comparable to those topping the CL ranking. Different from the latter, the Brazilian researchers in the Qualis top 20 have not been giving plenary lectures in the most prestigious conferences around the world, editing or reviewing papers for the most important journals in the profession, or inspiring $\mathrm{PhD}$ students and researchers from around the world.

In fact, the Qualis index is not so different from a ranking that counts the number of papers of each researcher (weighting each published paper by the reciprocal of the number of authors). Table 3 shows the 20 researchers with the highest number of papers and their respective Qualis ranking. Interestingly, the top 14 in number of papers comprises everyone in the top 10 in the Qualis-based ranking. ${ }^{7}$

\footnotetext{
${ }^{5}$ I thank Daniel Cajueiro for this information.

${ }^{6}$ That is basically the same as excluding Professors Cajueiro and Tabak from the sample. There are researchers in the top 10 US departments that publish in non-Economic journals, but by and large, those in my sample are not in the Economics Qualis list.

${ }^{7}$ The Qualis ranking now excludes Professors Cajueiro and Tabak. The outlier in this table is Professor Marcelo Resende e Silva (UFRJ), who has published a few papers in journals such 
Table 3

Top 20 researchers in number of papers

\begin{tabular}{lllll}
\hline Qualis ranking & & Qualis pts & \# papers \\
1 & Peter Phillips & Yale & 1442,50 & 27,33 \\
2 & John List & Chicago & 1376,67 & 16,15 \\
3 & James J. Heckman & Chicago & 910,83 & 11,70 \\
4 & Daron Acemoglu & MIT & 723,33 & 9,53 \\
90 & Marcelo Resende M e Silva & UFRJ & 335,00 & 9,50 \\
7 & Fuhito Kojima & Stanford & 685,00 & 9,00 \\
5 & Serena Ng & Columbia & 706,67 & 8,17 \\
8 & Matthew O. Jackson & Stanford & 666,67 & 7,87 \\
15 & Mauro Boianovsky & UNB & 570,00 & 7,50 \\
11 & Robert Townsend & MIT & 633,33 & 7,50 \\
13 & Liran Einav & Stanford & 602,50 & 7,50 \\
6 & Angus S. Deaton & Princeton & 690,83 & 7,33 \\
10 & Paulo Klinger Monteiro & EPGE & 653,33 & 7,33 \\
9 & Jonathan Gruber & MIT & 661,67 & 7,08 \\
18 & Mihai Manea & MIT & 560,00 & 7,00 \\
22 & Rubens Penha Cysne & EPGE & 542,50 & 7,00 \\
23 & Martin Feldstein & Harvard & 530,00 & 7,00 \\
27 & Don Andrews & Yale & 500,00 & 7,00 \\
33 & Ulrich K. Müller & Princeton & 470,00 & 7,00 \\
38 & Roger Myerson & Chicago & 450,00 & 7,00 \\
\hline
\end{tabular}


As pointed out by Novaes (2008), Brazilian researchers produce a large number of papers, but the average impact of each of those papers is small by international standards. By making little distinction among journals, Qualis gives a very high weighting to quantity and a low weighting to quality.

Figure 3 depicts the points attributed to each of the top 10 researchers in each institution according to the Qualis ranking. Each line represents a department and the horizontal axis shows the rank of a researcher in his/her department according to the Qualis ranking. There is still a gap between the top 10 US departments and the top 10 Brazilian departments, but at the top the gap is much smaller.

Figure 3

Most productive researchers in each institution (Qualis index)

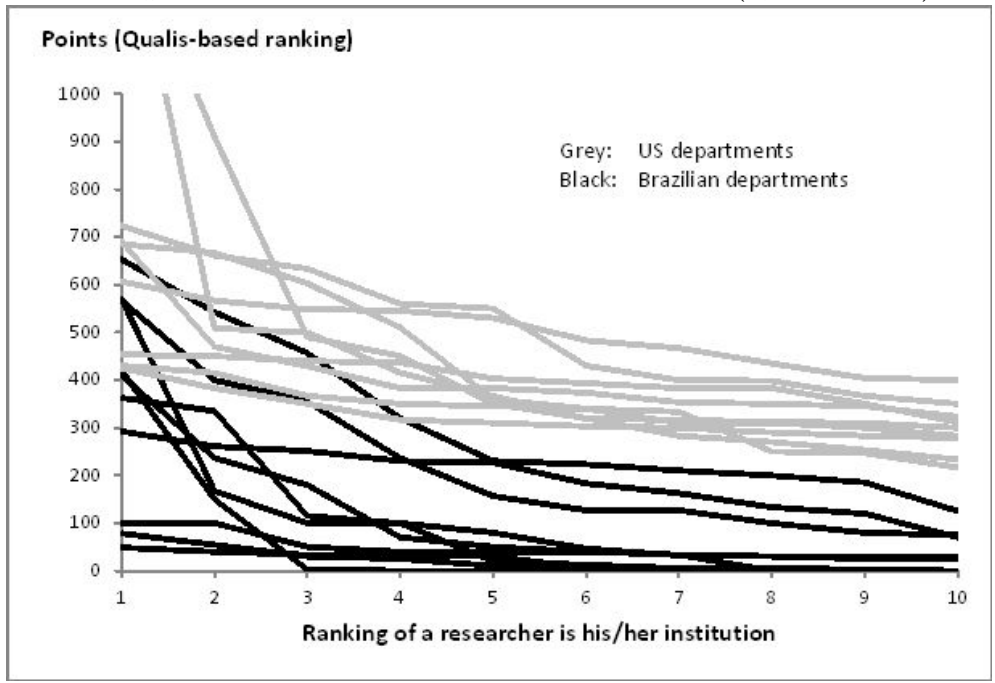

As shown in Figure 4, the Qualis index implies that the institions from Rio combined (EPGE, PUC and UFRJ) would be better than U Penn, and a combination of the institutions from Sao Paulo (EESP and USP) would not be very far off. Since, within the same city, students in one institution can take courses in the others, interact with researchers and attend seminars, students and researchers in Rio would be exposed to researchers of a similar level of those in the some US top-10 departments, according to the Qualis ranking. Needless to say, the demand from international students and researchers for places in Doctorate programmes and post-doctoral positions does not quite match the results of this ranking.

as Economics Bulletin and Review of Industrial Organization that are in the CL ranking but, for some reason, absent from the Qualis list of papers. 
Figure 4

Rio and São Paulo as a whole, according to the Qualis index

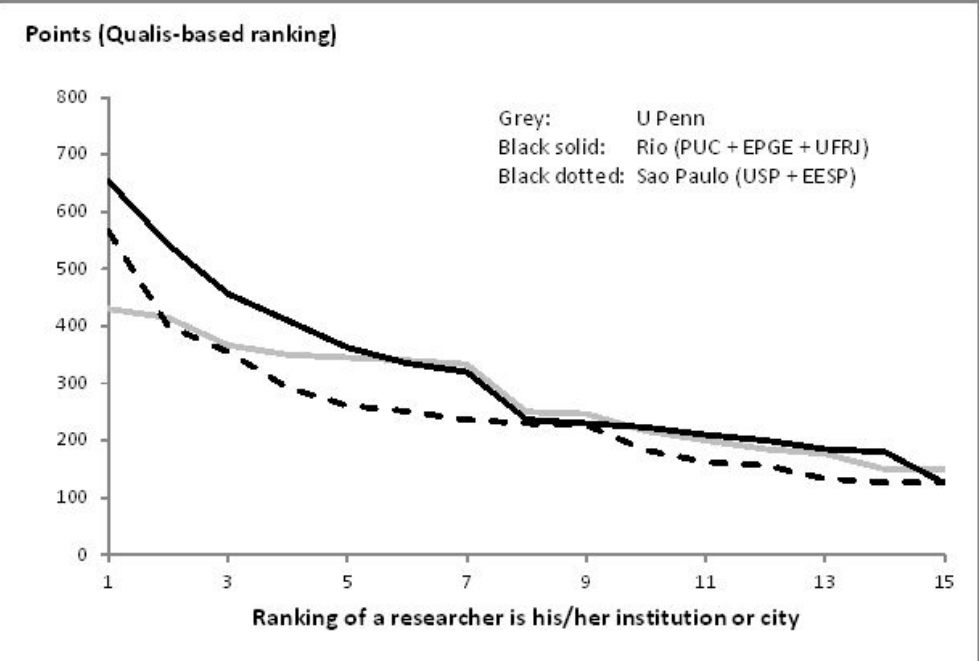

\subsection{Brazilian researchers: Qualis $\times$ CL index}

The analysis so far highlights some important problems with the Qualis ranking: by making little distinction among journals, it puts too much emphasis on the number of papers published. The small distinction between journals is apparent in Figure 1: while curves representing different international rankings have a relatively similar profile, the Qualis curve is much more flat.

Still, it is not clear whether the Qualis measure distorts the ranking of researchers in Brazilian institutions and how large the distortion is. A key question is: how correlated are the points Brazilian researchers get according to those different measures? The answer is depicted in Figure 5.

Panel (a) of Figure 5 shows the points attributed to each research according to the Qualis list and the CL ranking. As one would expect, the correlation between both measures is positive, but it is not very large. Interestingly, the graph in panel (a) resembles that in panel (b), which shows the CL points and the number of papers attributed to each researcher. Panel (c) shows that this relationship is not a coincidence: Qualis points and number of papers are strongly correlated when we consider Brazilian researchers only - consistently with the analysis in subection 3.2. The $R^{2}$ of a regression of Qualis points on number of papers is around $85 \%$ - in contrast, the $R^{2}$ of a regression between CL points and number of papers is around $27 \% .^{8}$

What if we control the relationship between CL points ans Qualis points for

\footnotetext{
${ }^{8}$ The $R^{2}$ is not significantly affected by including a constant as a regressor.
} 
Figure 5

CL points, Qualis points and number of papers

(a)

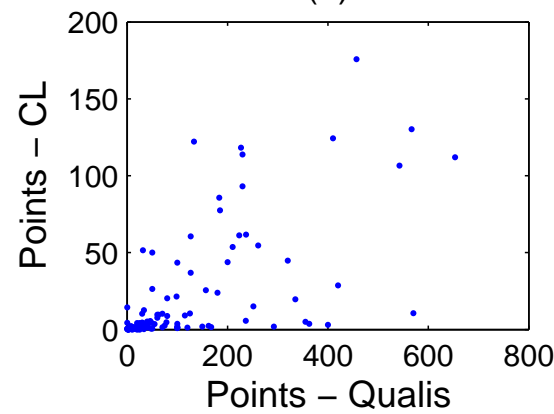

(c)

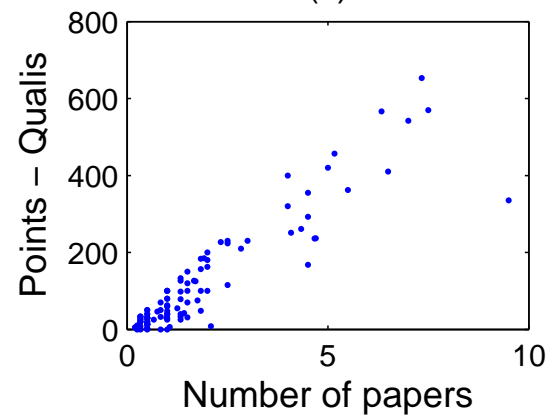

(b)

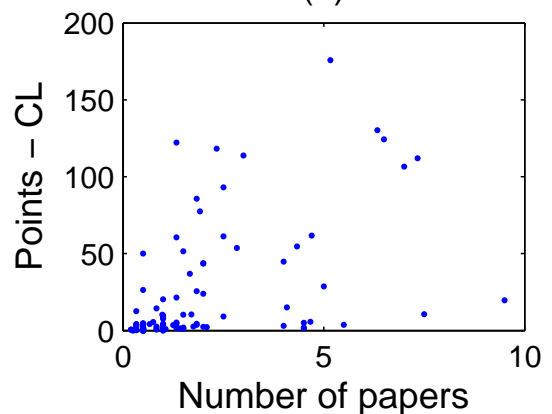

(d)

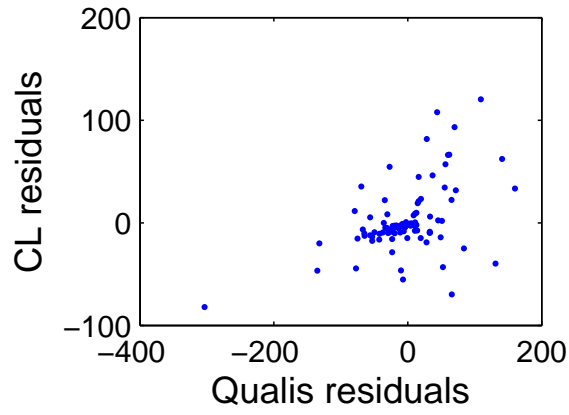


the number of papers? Panel (d) of Figure 5 shows the residuals of a regression of CL points on the number of papers (CL residuals) in the vertical axis and the residuals of a regression of Qualis points on the number of papers (Qualis residuals) in the horizontal axis. The Frisch-Waugh-Lowell theorem states that a regression of CL residuals on Qualis residuals is the same as a regression of CL points on Qualis points controling for the number of papers. Hence panel (d) of Figure 5 is a graphical representation of that regression. Except for the concentration of points close to $(0,0)$, one would never think that CL points and Qualis-points intend to measure the same thing. The $R^{2}$ of this regression is $22.7 \%$, a very low $R^{2}$ for what should be a regression of right shoes on left shoes.

The conclusion is that at least one of the two criteria cannot be used as a measure of research output, they are not measuring the same thing. There are two main reasons for such a large divergence between those two measures:

1. As shown in Figure 1, the Qualis list attributes a disproportionately large value to less prestigious journals, around 20 times more than the CL index and even more if compared to other methodologies. In line with the argument in Novaes (2008), the Qualis list rewards the production of a large number of papers, but not the production of very influential papers.

2. As pointed out by Silva (2009), some journals with a low impact factor (and hence a low position in the CL rankings) are classified as A1 or A2 in the Qualis list.

\section{Conclusion}

Qualis, the set of criteria used by the Brazilian Ministry of Education to assess our research output, does not provide a good measuring stick.

It is not clear that the impact of research on the scientific study of Economics should be the main ingredient for assessing the productivity of Brazilian researchers. Qualis needs to provide incentives for researchers and, in practice, it is very important to distinguish those with a relatively small research impact from those who haven't been producing at all. I doubt that the optimal way to provide incentives for Brazilian researchers will come from a linear mapping between research impact and rewards. Moreover, it might be socially optimal to provide incentives for research on Brazilian specific topics, and plenty of that might end up being published in Brazil.

Consequently, the evaluation of Brazilian academics could take into account different criteria besides the international impact of research. I stop here. The optimal way to provide incentives for Brazilian researchers constitutes a very interesting problem of mechanism design, but is way beyond the scope of this paper.

My point is a different one: research output in Brazil has not been properly measured, and it should be. For many students and professionals, the fundamental 
criteria for evaluating a department is its research impact on the academic community, usually proxied by something like the CL ranking. That is how researchers around the world evaluate their peers, that is what drives academic reputations of universities, that is why the likes of Harvard and MIT are considered to be the best.

\section{References}

Combes, P.-P. \& Linnemer, L. (2010). Inferring missing citations: A quantitative multi-criteria ranking of all journals in economics. Working Paper.

Faria, J. R., Araujo Jr, A. F., \& Shikida, C. D. (2007). The international research of academic economists in Brazil: 1999-2006. Economia Aplicada, 11:387-406.

Issler, J. V. \& Ferreira, R. (2004). Avaliando pesquisadores e departamentos de economia no Brasil a partir de citações internacionais. Pesquisa e Planejamento Econômico, 34:491-538.

Kalaitzidakis, P., Mamuneas, T. P., \& Stengos, T. (2003). Rankings of academic journals and institutions in economics. Journal of the European Economic Association, 1:1346-1366.

Kodrzycki, Y. K., , \& Yu, P. (2006). New approaches to ranking economics journals. Contributions to Economic Analysis and Policy, 5(1). Article 24.

Krapf, M. (2011). Research evaluation and journal quality weights: Much ado about nothing? Zeitschrift für Betriebswirtschaft, 81:5-27.

Laband, D. N. \& Piette, M. J. (1994). The relative impacts of economics journals: 1970-1990. Journal of Economic Literature, 32:640-666.

Novaes, W. (2008). A pesquisa em economia no Brasil: Uma avaliação empírica dos conflitos entre quantidade e qualidade. Revista Brasileira de Economia, 62:467-495.

Prado Jr, C. (1942). Formação do Brasil Contemporâneo. Companhia das Letras.

Silva, S. (2009). Going parochial in the assessment of the Brazilian economics research output. Economics Bulletin, 29:2847-2867. 